\title{
Ценностно-оценочные принципы в кинокритике
}

\author{
Саенкова-Мельницкая Л. П. \\ Белорусский государственный университет, \\ Республика Беларусь, 220030, г. Минск, пр. Независимости, 4 \\ E-mail: sayenkova@gmail.com
}

\begin{abstract}
Аннотация. Кинокритика как особый вид медиапрактики оказывает воздействие на развитие киноискусства, способствует реализации образовательно-просветительской, культурнопросветительской функций, влияет на развитие и укрепление культурного статуса журналистики. Кинокритика является важным инструментом в поисках смысловой и эстетической упорядоченности активно развивающегося кинопроцесса. Несмотря на внимание к сущностным особенностям этого вида творческой деятельности со стороны исследователей медиадискурса, такие категории, как ценностные основания и оценочные принципы остаются недостаточно изученными. Целью данного исследования является анализ ценностно-оценочных подходов в кинокритике в диахроническом и синхроническом аспектах. В результате исследования были выявлены доминирующие ценностные подходы в кинокритических текстах в разные исторические периоды, обоснована необходимость следования тем оценочным принципам, которые помогают обнаружить степень художественной состоятельности произведения.
\end{abstract}

Ключевые слова. Кинокритика, журналистика, ценностное значение, публикации, критерии, оценочное высказывание, критическо-оценочная репрезентация.

Для цитирования: Саенкова-Мельницкая Л.П. 2021. Ценностно-оценочные принципы в кинокритике. Вопросы журналистики, педагогики, языкознания, 40 (2): 175-183. DOI: $10.52575 / 2712-7451-2021-40-2-175-183$

\section{Value-evaluation principles in film criticism}

\author{
Ludmila P. Sayenkova-Melnitskaya \\ Belarusian State University, \\ 4 Independence Av., Minsk, 220030, The Republic of Belarus \\ E-mail: sayenkova@gmail.com
}

\begin{abstract}
Film criticism as a special type of media practice, on the one hand, has an impact on the development of film art, on the other, affects the development and strengthening of the cultural status of journalism. Film criticism is an important tool in the search for the semantic and aesthetic meanings of the actively developing film process. Despite the attention from the media discourse researchers, film critics and cinematographers to the essential features of this type of creative activity such categories as value bases and evaluative principles remain insufficiently studied. The purpose of this study is to analyze the value-evaluation principles in film criticism in diachronic and synchronic aspects. The result of the research is the identification of the dominant value principles in film critical texts in different historical periods, justification of the need to follow the evaluation criteria that reveal the degree of artistic consistency of the film production.
\end{abstract}

Keywords. Film criticism, journalism, value meaning, publications, criteria, evaluative statement, critical-evaluative representation.

For citation: Sayenkova-Melnitskaya L.P., 2021. Value-evaluation principles in film criticism. Issues in Journalism, Education, Linguistics, 40 (2): 175-183 (in Russian). DOI: 10.52575/2712-7451-2021-40-2$175-183$ 


\section{Введение}

Кинокритика является неотъемлемой частью той разновидности журналистики, которая позиционируется как культурно-просветительская [Лазутина, Распопова, 2012], культурологическая [Ильченко, 2019] либо является частью того информационного дискурса, который определяется как «культурологическая проблематика» [Дедкова, 2008] или как «тема культуры и искусства в СМИ» [Бондарева, 2004]. С учетом медиаобразовательного потенциала некоторые исследователи кинокритику рассматривают как разновидность медиакритики [Короченский, 2003; Федоров, 2013]. Процессы социокультурной и медиатрансформации позволили кинокритику рассматривать в контексте артжурналистики [Сагдуллаев, 2014; Мясникова, 2014; Груздева, 2019; Самсонова, 2021], журналистики сферы досуга [Журналистика сферы..., 2012]. Одну из главных целей журналистики, которая репрезентирует художественную культуру, можно было бы определить как возможность «ориентировать общество в духовных богатствах, накопленных культурным слоем, и давать оперативное знание о его приросте и возможностях применения, помогая публицистическими средствами выявить значение новых артефактов и их роль в разрешении общественных и личных актуальных проблем» [Лазутина, Распопова, 2012, с. 213]. Кинокритика входит в состав того медийного контента, где реализуется функция «ценностного ориентирования», способствуя приобщению массмедиа к «структуре ценностных отношений» [Лазутина, 2013].

Кинокритика, предполагающая системную репрезентацию кинопроцесса в медиасфере, возникла одновременно с появлением первых фильмов. В течение всей истории развития киноискусства кинокритика была объектом пристального внимания кинематографистов. С. Эйзенштейн, Вс. Пудовкин, А. Довженко, С. Васильев рассматривали кинокритику с точки зрения наличия определенного инструментария для представления кинопроизведений. Кинокритика анализировалась как вид литературно-художественной критики в исследованиях искусствоведов, эстетиков. В отдельных работах кинокритиков, киноведов исследовались методологические подходы в репрезентации фильмов, определенные особенности представления кинопроцесса в средствах массовой информации. В белорусском исследовательском кинодискурсе есть издание, где представлены фрагменты многочисленных рецензий на белорусские фильмы, созданные в период с 1926 по 1983 гг. [Авдеев, Зайцева, 1996; Авдеев, Зайцева, 2000].

В данном исследовании обращается внимание на ценностно-оценочные основания кинокритики как на сущностные параметры этого вида информационно-аналитической деятельности в журналистике. Актуальность этой темы предопределена несколькими факторами. Во-первых, ситуацией в самой киноиндустрии, когда при активном наращивании технического и технологического потенциала увеличивается степень финансовокоммерческих возможностей этой области развлечений, что при количестве выпускаемых фильмов создает ситуацию «киноброуновского» движения. Кинокритические стратегии ценностного ориентирования в данном случае нужны и важны для того, чтобы «придать смысл тому, что происходит в кино» [Ямпольский, 2012], что соответствует запросам той части аудитории, которая пытается «увидеть в мире хаоса порядок и смысл» [Ямпольский, 2012]. Во-вторых, необходимостью сохранения качественного информационного сегмента при увеличивающейся доли развлекательного и фейкового контента в современных средствах массовой информации. В-третьих, реализацией тех сущностно важных функций кинокритики, которые сформировались в течение более чем столетней истории ее развития культурно-просветительской, познавательно-оценочной, художественно-эстетической. Кинокритике, в той или иной степени испытывающей влияние массовой культуры, попрежнему свойственно стремление «дополнить... художественный талант способностью разумного критического суждения, непосредственность... творчества - теоретической опосредованностью и рациональным знанием норм, правил, принципов, критериев худо- 
жественно-эстетического совершенства; сочетать создание ценностей, продиктованных творческой интуицией, с сознательной их оценкой, теоретической рефлексией» [Кондаков, 1997]. В исследованиях разных лет, где на теоретическом уровне осмысливались проблемы критики и кинокритики в частности, оценочность рассматривалась сквозь призму категорий объективного и субъективного [Баранов, Бочаров, Суровцев, 1982], в контексте методологических проблем [Зайцева, 1984], в обобщении практического опыта [Бондарева, 1983]. Однако в научно-теоретическом дискурсе оценочность в кинокритике не рассматривалась как текстообразующая категория, проявляющая ценностные установки, целеполагание как автора, так и редакции. Важным моментом в изучении ценностно-оценочных оснований в кинокритике является анализ кинокритического дискурса в контексте конкретных историко-культурных реалий.

Методология исследования основывается на дискурсном подходе к кинокритическому тексту с точки зрения ценностных установок и выражения оценочных позиций. Для достижения поставленной цели использовались синхронический, диахронический методы анализа, а также метод системно-целостного анализа.

\section{Ценностно-оценочный потенциал кинокритического дискурса: практический аспект}

Ценностное значение кинокритики заключается в раскрытии тех смыслов в кинопроизведении, кинофактах, которые являются важными как для художественноэстетического образования, этического воспитания, духовно-нравственного становления, так и для мировоззренческого просвещения. Когнитивная сущность кинокритики предопределена продуцированием собственных смыслов, соотнесенных, извлеченных из произведения киноискусства, творческого, личностного потенциала создателей этих произведений. В кинокритике актуализируется информация, имеющая отношение, с одной стороны, к кинематографическим реалиям, а с другой - социокультурному контексту. Она обладает ценностным значением, как в осмыслении конкретной ситуации, так и в понимании общечеловеческих смыслов. Кинокритические тексты наравне с другой информацией, представленной в том или ином издании (массовом общественно-политическом или специализированном), участвуют в обнародовании важных проблем, осмысление, а порой и решение которых определяет важную стратегию дальнейщего социокультурного развития. Тексты в СМИ, с одной стороны, отражают реальность, а с другой, отражают ценностное наполнение этой реальности. Адресат не только получает информацию, но и соотносит эту информацию со своей шкалой ценностей, предопределенной образованием, воспитанием, культурным багажом, уровнем развития общества, ментальными характеристиками. Показателем такой «включенности» потребителя информации в процесс открытия новых смыслов, соотнесенности этой информации со своими «индивидуальными запасниками» являются отзывы читателей (зрителей) на опубликованные тексты. Когда-то это были письма в редакции, сегодня это комментарии, отзывы на сайтах редакций, на электронной почте авторов, «клики», реплики в социальных сетях. Иногда эти письма высказывание своей точки зрения на фильм, кинособытие; иногда - выражение отношения к публикации. Контент любой публикации - положительной или отрицательной - активизирует читательско-зрительскую реакцию в определении базовых ценностей. Перефразировав название одной из корреспонденций «Фильмы смотрят нас» ${ }^{1}$, можно сказать, что публикации тоже «смотрят нас», что означает степень выявления в читателе (зрителе) определенных ценностных установок.

${ }^{1}$ Андрей Звягинцев. 2018. Не только мы смотрим фильмы, но и фильмы смотрят нас. URL: https://urfu.ru/ru/news/25588/ (дата обращения 05.12. 2018). 
Кинокритические публикации по содержанию, жанрово-тематическим параметрам, уровню авторской рефлексии, целеполагающим установкам бывают разные: информирующие, просвещающие, образовывающие, вовлекающие, побуждающие, рекламирующие. Не в каждой публикации есть собственно критическое отношение автора к фильму, событию, кинофакту, киноперсоне. Независимо от «критической массы» кинокритическая публикация всегда вызывает определенную читательскую реакцию, поскольку в таких текстах заложен диалогический эффект. Восприятие медиатекста свидетельствует об уровне медиакультуры, степени развития личности, «способной воспринимать, анализировать..., заниматься медиатворчеством, усваивать новые знания» [Саенкова, 2010]. В истории кинокритики были такие факты, когда публикация давала повод для продолжительных дискуссий. Так было в свое время с фильмами ныне признанных киноклассиков М. Хуциева («Июльский дождь»), В. Шукшина («Калина красная»), А. Кончаловского («Романс о влюбленных»), Н. Михалкова («Неоконченная пьеса для механического пианино»), А. Германа («Мой друг Иван Лапшин»), А. Тарковского («Зеркало»), Л. Шепитько («Восхождение»). Зрительские письма во многом предопределяли кинокритические дискуссии, в которых отражались поиски гражданской самоориентации, культурноисторической идентичности, нравственных смыслов. В прессе 1980-х гг. были популярны публикации разных мнений на один фильм, диалоги кинокритиков. Предметом обсуждения становились кинопроизведения, где герои оказывались в ситуации морального выбора. Такие дискуссии изначально были рассчитаны на диалогический эффект. Определению ценностных установок способствовали не только рецензии или диалоги, но и такие некогда активно востребованные жанры кинокритики, как творческий портрет, зарисовка, эссе [Саенкова-Мельницкая, 2014]. Максимально используя возможности кинодискурса для диалога с читательской аудиторией, акцентируя внимание на той информации, которая могла вызвать реакцию адресата, способствующую выявлению базовых ценностей, издание и автор влияли на реализацию важного предназначения журналистики - участию в ценностном ориентировании.

Ценностное ориентирование, заложенное в кинокритических текстах, предопределено авторско-редакционным целеполаганием и имеет многовекторную направленность: в сторону аудитории, авторской позиции, редакционных предпочтений. Ценность является одним из важных параметров любой целеполагающей системы, будь то человек, учреждение, среда, общество. Ценностное самоопределение начинается с авторского выбора: в современном культурно-просветительском медиадискурсе именно автор выбирает и предлагает информационный повод, определяет ценностную значимость кинофакта, изначально соотнося его с параметрами культуры. Несмотря на то, что экранная культура иногда продуцирует артефакты, далекие от классических этических и нравственных норм, кинокритик, как правило, делает выбор в пользу того произведения, где воплощены универсальные общечеловеческие ценности, принимающие когнитивную, «знаниевую» форму [Микешина, 2007]. Выбор автора свидетельствует о его ценностно-эстетических предпочтениях. Через чтение и восприятие текста читатель получает информацию не только о произведении, факте, событии, но и об авторе как о субъекте - создателе кинокритического произведения. Авторская самобытность в кинокритическом тексте проявляется не только благодаря индивидуальной манере представления кинопроизведения, авторскому стилю, но и благодаря постулированию своих ценностных предпочтений. В 1969 г. на экраны вышел белорусский фильм «Жди меня, Анна!» (реж. В. Виноградов). В общем хоре критических голосов преобладала негативная оценка. Фильм критиковали за «внешнюю поэтичность», которая не повлияла на раскрытие драмы времени, за драматургические изъяны, «дебри изобразительного изыска», «надуманный эксцентризм» [Белов, Хлоплянкина, 1970; Дьяченко, 1970]. Среди многочисленных публикаций в общесоюзной и белорусской прессе особенно стала заметной рецензия, опубликованная в газете «Советская Белоруссия». Журналист обратила внимание на то, что соотносится с ее личными 
приоритетами: «Мы словно прикоснемся к истокам человеческой личности... Такие минуты душевной обнаженности человека редки в жизни, и мы бываем благодарны художникам, запечатлевшим этот миг, ибо в такие минуты мы и себя глубже познаем...» [Манаева, 1969]. В этой рецензии обнаружились авторская проницательность, умение заметить сущностные особенности режиссерского посыла, экзистенциальные ценности.

В ценностно-оценочном восприятии кинокритического текста есть несколько субъектных уровней. На первом уровне проявляется такое событие, как встреча двух авторов, когда авторский критический текст оценивается как сотворчество. Запечатление глубинного содержательно-ценностного плана фильма возможно при условии, когда критик сам наделен способностью ценностного ориентирования. Второй уровень предопределяет то, что, возможно, было не сразу заметно для читателя (зрителя) в фильме, - то встреча читателя с художественным произведением посредством кинокритического текста. Третий уровень обнаруживает равноправную встречу трех субъектов: автора, критика, читателя.

Уровни ценностного ориентирования в кинокритических текстах проявляются поразному в зависимости от времени. Вышедший в 1966 г. фильм белорусского кинорежиссера Виктора Турова «Я родом из детства» сразу стал заметным явлением в многонациональном советском киноискусстве. Тем не менее, в многочисленных рецензиях преобладал негативный акцент. Фильм упрекали в том, что авторам не хватило глубины в раскрытии характеров персонажей, правды в показе драматических моментов последнего года войны, что «авторы фильма только описывают жизнь, но не познают ее», что «получились этюды... но снять целостную, единую по замыслу картину режиссер не сумел» [Блейман, 1967]. Спустя годы к фильму обратились критики другого поколения, увидевшие в нем то художественное наполнение, которое не открылось ранее. То, что некогда представлялось недостатком, через несколько лет обернулось художественным достоинством: эскизность, лиричность, недосказанность. «“Я родом из детства” был одним из первых в шестидесятые годы фильмов, в которых на смену традиционному сюжетосложению пришла драматургия более естественная, раскованная, сопрягающая события не по законам непрерывно развивающегося действия, а по сложным ассоциативным связям» [Павлючик, 1985, с. 42]. «В поле зрения авторов оказывается не столько повседневная жизнь героев, сколько эмоциональные удары, которые в те годы формировали человеческие души... Мир в фильме... видится преимущественно детскими глазами, потому естественно, что в его изображении описание преобладает над анализом, истолкованием» [Ратников, 1985, с. 127-128]. Авторы рецензий, наделенные опытом другого оптического видения, сформированного десятилетиями позже, сделали акценты на важной ценностной доминанте фильма, определившей стиль повествования, - атмосфера, интонация, ритм. Ценностно-эстетический потенциал автора-критика предопределил иную степень раскрытия художественноценностного наполнения произведения. Установление ценности предполагает процесс оценивания. Понятие «оценка» в аксиологии определяется как то, что соотносится с нравственными и эстетическими идеалами. Как справедливо замечено философом Л.А. Микешиной, «ценности объективно не содержатся в вещах, их источником может быть только субъект, осуществляющий оценивание на основе ценностных представлений» [Микешина, 2007, с. 48]. С другой стороны, «оценочное высказывание предполагает наличие трех компонентов - объекта, субъекта и основания оценки» [Гаранина, 2013, с. 28].

Кинокритика, имеющая дело с образами реальности, запечатленными в экранной форме, репрезентирует «картину мира с позиций визуальной метафоры» [Микешина, 2007, с. 5]. В кинокритических рецензиях содержательные смыслы раскрываются в единстве с анализом киноязыка, который имеет тенденцию к технологическому усложнению и метафорической образности. Открыть смыслы авторских месседжей, передаваемых через многообразие художественных деталей, образов, уловить стилеобразующую интонацию, ритм бывает непросто для массового зрителя, что актуализирует кинокритическую деятельность. В XXI в. с усилением процессов коммерциализации киноиндустрии, увеличе- 
нием доли развлекательного киноконтента повышается и потребность в критическооценочной репрезентации, квалифицированной интерпретации кинопроизведений.

В разные годы в кинокритике оформлялись разные ценностно-оценочные подходы в репрезентации произведения киноискусства. В начале 1910-х гг. главной ценностной установкой была поддержка самого факта появления кино, потому оценочной доминантой была рекламная составляющая. Постепенно рекламные элементы уступили место размышлению над содержанием, потому с середины 1920-х гг. в публикациях о кино стал доминировать другой оценочный принцип - нарративный, когда отношение к фильму выражалось посредством авторской интерпретации сюжета. В 1930-е гг. в советском кино постоянной была тема строительства нового общества, формирование нового человека. В газетно-журнальных публикациях того времени оценочный подход предполагал выявление социально значимых линий, конфликтов, характеристик героев. В 1940-е гг. в публикациях о кино доминировала патриотическая тема. Одним из самых важных ценностных акцентов был призыв к борьбе, позиционирование советского народа как борющегося за свободу.

В послевоенное время, в котором ощущалась атмосфера мирной жизни, появилась возможность перейти к новому формату фильмов (комедии, фильмы-спектакли, сатирические кинопроизведения) и к новым ценностным установкам в кинокритике, когда большее внимание стало уделяться таким понятиям, как художественная выразительность, правда характеров, драматургическая целостность. Шестидесятые годы в мировой кинематографии были отмечены поиском новой образности, эволюцией киноязыка, особым уровнем запечатления авторской индивидуальности. Кинокритики стали обращать внимание на эстетическую целостность фильма, анализируя «поэтичность замысла», «духовный мир героев», «эффектные киноприемы», «богатство ассоциаций», «выразительность деталей», «атмосферу времени». Оценочной доминантой в кинокритике 1960-х гг. оставался критерий правды, психологии характеров, но при этом добавился критерий эстетической значимости как наиболее важный. В публикациях о кино в авторской оценке преобладало собственно критическое отношение. Критические замечания высказывались относительно фильмов, которые и в то время становились заметными произведениями, а позже были признаны киноклассикой: «Добро пожаловать, или Посторонним вход воспрещен», «Андрей Рублев», «Иваново детство», «История Аси Клячиной, которая любила да не вышла замуж», «Скверный анекдот», «Интервенция», белорусские фильмы «Через кладбище», «Третья ракета», «Восточный коридор». В 70-е годы на новом уровне продолжилось осмысление героики военного времени, что предопределило создание драмы героического противостояния. Ценностным центром кинорецензий было осмысление драматургии конфликта, выявление художественной и документальной правды характеров: «А зори здесь тихие», «Они сражались за Родину», «Полонез Огинского», «Венок сонетов», «Долгие версты войны». Это было время прихода в кино молодых авторов, появления стилистически новых фильмов известных мастеров и время экранизаций: «Неоконченная пьеса для механического пианино», «Белая птица с черной отметиной», «Дикая охота короля Стаха», «Гамлет Щигровского уезда», «Жизнь и смерть дворянина Чертопханова», «Кортик», «Калина красная», «Зеркало», «Ключ без права передачи». Поскольку это было десятилетие дебютов и последующих картин молодых режиссеров, то ценностный смысл приобрела тема осмысления творческой эволюции киномастеров. В 1980-е гг. были созданы фильмы, в которых был запечатлен новый уровень осмысления событий прошлого и настоящего. Внимание к фильмам неожиданной кинематографической формы стало главной составляющей оценочного подхода. Ценностной установкой кинокритиков было объяснение документальной стилистики, новых выразительных средств, иного уровня художественной образности в таких фильмах, как «Мой друг Иван Лапшин», «Чужая вотчина», «Иди и смотри», «Покаяние», «Холодное лето пятьдесят третьего». В 1990-е гг., в период социокультурной трансформации, изменилась журналистика, государственное кинопроизводство переживало упадок. В публикациях о кино акцентировалось внимание на 
развлекательности, эпатажности, консьюмеризме. В печати изменилась система авторства: кино (как и другие виды искусства) стали представлять не столько приглашенные критики, сколько штатные журналисты. Кинокритика постепенно стала трансформироваться в киножурналистику. Понятие «журнализм» применительно к текстам о кино в большей степени содержало отрицательную коннотацию: волюнтаризм, субъективизм, отсутствие эстетических критериев [Критика критики, 2003; Агафонова, 2014] Основной ценностной установкой публикаций о кино в массовой прессе того времени было соответствие вкусам и ожиданиям не очень взыскательной в художественном плане, не очень подготовленной к эстетическому восприятию аудитории. Кинопубликации становились частью того информационного контента, который входил в поле товарно-денежных отношений. В ценностно-оценочных подходах авторов кинокритических текстов постепенно стал доминировать рекламно-репрезентационный элемент, усиление прагматической функции оценки [Ли Линцзюань, 2018]. Ценностно-оценочные критерии, предполагающие представление художественной значимости произведения, способствующие реализации культуроформирующей функции как кинокритики, так и журналистики в целом возобновились с появлением авторских колонок о кино, с приходом нового поколения журналистов, специализацией которых стало освещение вопросов киноискусства.

\section{Заключение}

Оценочность является той категорией в кинокритических текстах, посредством которой проявляются авторские стратегии, редакционное целеполагание, жанровые форматы, формируются основные текстообразующие параметры. В различных историкокультурных контекстах, у разных авторов, выражающих свое мнение по поводу одного и того же события, факта, оценочность проявлялась по-разному, обнаруживая разные ценностные установки, подходы. В кинокритике, как и в любом другом виде литературнохудожественной критики, важно, чтобы ценностно-оценочные основания способствовали раскрытию универсальных культурных кодов, общечеловеческих смыслов. Ценностный потенциал кинокритики предопределен творческим характером этого вида деятельности. Творчество, реализуя идеи «созидания, совершенствования и возникновения... нового, никогда не бывшего ранее» [Фрольцова, 2003, с. 3], способствует самому главному: развитию и личностному раскрытию человека, «обретению человеком все большей свободы с тем, чтобы... максимально увеличить возможности личностной самореализации» [Фрольцова, 2003 с. 3].

Кинокритические тексты повышают степень культурной значимости издания, помогают реализовать культурно-просветительскую функцию журналистики, активно участвуют в художественно-эстетической ориентации аудитории, воссоздании ценностной картины мира. Ценностно-оценочные принципы, запечатленные в кинокритическом дискурсе, открывающие значимые смыслы, способствуют расширению художественнокоммуникативных возможностей и искусства кино, и гуманизации культуры в целом.

\section{Список источников}

1. Авдеев И., Зайцева Л. 1996. Все белорусские фильмы. Т.1. Игровое кино (1926-1970). Под ред. А.В. Красинского. Минск, Бел. навука, 240 с.

2. Авдеев И., Зайцева Л. 2000. Все белорусские фильмы. Т.2. Игровое кино (1971-1983). Под ред. А.В. Красинского. Минск, Бел. навука, 299 с.

3. Баранов В.И., Бочаров А.Г., Суровцев Ю.И. 1982. Литературно-художественная критика. М., Высшая школа: 207 с.

4. Белов Г., Хлоплянкина. Т. 1970. Мнимая поэтичность. Советский экран, 18: 4-5.

5. Бондарева Е.Л. 2004. Освещение литературы и искусства в СМИ. Минск, БГУ, 119 с.

6. Блейман М. 1967.Талантам мысли глубину. Советская культура, 23 янв. С.4.

7. Дьяченко В. 1970. Парадоксы современного фильма. Искусство кино, 12: 21-35. 
8. Журналистика сферы досуга. 2012. Под ред. Л.Р. Дускаевой, Н.С. Цветовой. СПб., Высш. школа журн. и мас. коммуникаций, 304 с.

9. Критика критики. Анкета «Искусство кино». 2003. Искусство кино, 12: 5-12. URL: http://old.kinoart.ru/archive/2003/12/n12-article2 (дата обращения 07.08.2010)

10. Лазутина Г.В., Распопова С.С. 2012. Жанры журналистского творчества. М., Аспект Пресc, 320 c.

11. Манаева Д.1969. О войне без войны. Советская Белоруссия, 20 нояб. С.4.

12. Павлючик Л.1985. От исповеди к эпосу. Судьба и фильмы Виктора Турова. М., Всесоюзн. бюро пропаганды киноискусства, 112 с.

13. Ратников Г. 1985. На экране Великая Отечественная. В кн. Красинский А.В. Современное белорусское кино. Под ред. А.В. Красинского, Е.Л. Бондаревой. Минск, Наука и техника: 88-136.

14. Цветова Н.С. 2019. Искусство в массмедиа. С-Пб., Издательство ВВМ, 91 с.

15. Ямпольский Михаил. 2012. Что такое кинокритика. URL: http://os.colta.ru/cinema/events/details/35533 (дата обращения 17. 07. 2014).

\section{Список литературы}

1. Агафонова Н. А. 2014. Искусствоведение как наука: Pro \& Contra. Артэфакт, 1: 89-93.

2. Бондарева Е.Л. 1983. Экран в разных измерениях. Минск, Изд-во БГУ, 271 с.

3. Гаранина Э.Ю. 2013. Оценочность в жанре кинорецензии. Вестник Кемеровского государственного университета, 2-2 (54): 28-31.

4. Груздева М.М. 2019. Современная арт-рецензия как отражение арт-сознания постмодернистской культуры (к постановке вопроса). Вопросы психолингвистики, 2 (40): 176-185.

5. Дедкова Т.Ф. 2008. Культурологическая проблематика. В кн.: Проблематика СМИ: информационная повестка дня. Под ред. М.В. Шкондина и др. М., Аспект Пресс: 143-178.

6. Ильченко С.Н. 2019. Культурология журналистики: объяснение понятий. Журнал Белорусского государственного университета. Журналистика. Педагогика, 1: 13-16.

7. Короченский А.П. 2003. Пятая власть? Медиакритика в теории и практике журналистики. Ростов н/Д., Изд-во Рост. ун-та, 280 с.

8. Лазутина Г.В. 2013. Печатные издания в процессе ценностного ориентирования аудитории: возможности и результаты. Вестник. Московского ун-та. Сер. 10. Журналистика, 6: 66-77.

9. Ли Линцзюань. 2018. Снижение категоричности оценки и прагматическая функция оценки в тексте кинорецензии. Филологические науки. Вопросы теории и практики, 7-2 (85): 343-347.

10. Микешина Л.А. 2007. Эпистемология ценностей. М., Рос. полит. энцикл., 439 с.

11. Мясникова М.А. 2014. Практическая подготовка арт-журналистов в рамках профессионального медиаобразования. Педагогическое образование в России, 12: 117-121.

12. Сагдуллаев К.К. 2014. Арт-журналистика в глобальном информационном пространстве. Austrian Journal of Humanities and Social Sciences, 3-4: 13-17.

13. Саенкова Л.П. 2010. Особенности современной медиакультуры в условиях глобализации. Социум и власть, 4 (28): 97-102.

14. Саенкова-Мельницкая Л.П. 2014. Понятия «жанр», «система жанров» в журналистике и кинокритике: предметные характеристики и факторы жанрообразования. Веснік БДУ. Cep IV. Філалогія. Журналістыка. Педагогіка, 4 (2): 82-85.

15. Самсонова А.А. 2021. Арт-журналистика. Речевые техники оценивания произведения искусства. С-Пб. Алетейя, 129 с.

16. Федоров А.В. 2013. Анализ аудиовизуальных медиатекстов. М., Директ-Медиа, 182 с.

17. Фрольцова Н.Т. 2003. Типология творческой деятельности в аудиовизуальной коммуникации. Минск, БГУ, 216 с.

\section{References}

1. Agaphonova N.A. 2014. Iskusstvovedenie kak nauka: Pro \& Contra. [Art history as a science: Pro \& Contra] Artefakt,1: 89-93.

2. Bondareva E.L. 1983. Ekran v raznych izmereniych [Screen in different dimensions]. Minsk, Publ. Belarusian State Univ. 271 p. 
3. Garanina E.Yu. 2013. Otsenochnost' v zhanre kinoretsenzii [Appreciation in the genre of film review]. Bulletin of Kemerovo State University, 2-2 (54): 28-31.

4. Gruzdeva M.M. 2019. Sovremennaya art-retsenziya kak otrazhenie art-soznaniya postmodernistskoy kul'tury (k postanovke voprosa) [Contemporary art review as a reflection of the art consciousness of postmodern culture (to the question)]. Yournal of Psycholinguistics, 2 (40): 176-185.

5. Dedkova T.F. 2008. Kul'turologicheskaya problematika [Cultural Problems]. In: Problematika SMI: informatsionnaya povestka dnya [Media issues: information agenda]. Eds. M.V. Shkondin, G.S. Vychuba, T.I. Frolova. M., Publ. Aspekt Press: 143-178.

6. Il'chenko S.N. 2019. Kul'turologiya zhurnalistiki: ob"yasnenie ponyatiy [Culturology of journalism: explanation of concepts]. Journal of the Belarusian State University. Journalism, 1: 13-16.

7. Korochenskiy A.P. 2003. Pyataya vlast'? Mediakritika v teorii i praktike zhurnalistiki [Fifth Estate? Media criticism in the theory and practice of journalism]. Rostov n/D., Publ. Rost. un-ta, 280 p.

8. Lazutina G.V. 2013. Pechatnye izdaniya v protsesse tsennostnogo orientirovaniya auditorii: vozmozhnosti i rezul'taty [Printed publications in the process of value orientation of the audience: opportunities and results]. Vestnik Moskovskogo Universiteta. Seriya 10. Zhurnalistika, 6: 66-77.

9. Li Lintszyuan'. 2018. Snizhenie kategorichnosti otsenki i pragmaticheskaya funktsiya otsenki $\mathrm{v}$ tekste kinoretsenzii [Decrease in the categorical evaluation and the pragmatic function of evaluation in the text of a film review]. Philology. Theory \& Practice, 7-2 (85): 343-347.

10. Mikeshina L.A. 2007. Epistemologiya tsennostey [Epistemology of values]. M., Publ. Ros. polit. entsikl., 439 p.

11.Myasnikova M.A. 2014. Prakticheskaya podgotovka art-journalistov v pamkach professionalnogo mediaobrazovania [Practical training of art journalists in the framework of professional media education]. Pedagogicheskoe obrazovanie v Rossii, 12: 117-121.

12.Sagdullaev K.K. 2014. Art's journalism in the global information space. Austrian Journal of Humanities and Social Sciences, 3-4: 13-17.

13.Saenkova L.P. 2010. Osobennosti sovremennoy mediakul'tury v usloviyakh globalizatsii [Features of modern media culture in the context of globalization]. Society and Power,4 (28): 97-102.

14.Saenkova-Mel'nitskaya L.P. 2014. Ponyatiya «zhanr», «sistema zhanrov» v zhurnalistike i kinokritike: predmetnye kharakteristiki i faktory zhanroobrazovaniya [The concepts of "genre", "system of genres" in journalism and film criticism: subject characteristics and factors of genre formation]. Journal of the Belarusian State University. Journalism and Pedagogics, 4 (2): 82-85.

15.Samsonova A.A. 2021. Art-zhurnalistika. Rechevye tekhniki otsenivaniya proizvedeniya iskusstva [Art Journalism. Speech techniques for evaluating a work of art]. S-Pb., Publ. Aleteyya, 129 p.

16.Fedorov A.V. 2013. Analiz audiovizual'nykh mediatekstov [Analysis of audiovisual media texts]. M., Publ. Direkt-Media, 182 p.

17.Frol'tsova N.T. 2003. Tipologiya tvorcheskoy deyatel'nosti v audiovizual'noy kommunikatsii [Typology of creative activity in audiovisual communication]. Minsk, Publ. BGU, 216 p.

\section{ИНФОРМАЦИЯ ОБ АВТОРЕ}

Саенкова-Мельницкая Людмила Петровна, кандидат филологических наук, доцент, заведующая кафедрой литературнохудожественной критики факультета журналистики Белорусского государственного университета, г. Минск, Республика Беларусь

\section{INFORMATION ABOUT THE AUTHOR}

Lyudmila P. Saenkova-Melnitskaya, Candidate of Philology, Associate Professor, Head of the Department of Literary and Artistic Criticism of the Faculty of Journalism of the Belarusian State University, Minsk, Republic of Belarus 